\title{
Hydrodeoxygenation of Bio-Oil on Bimetallic Catalysts: From Model Compound to Real Feed
}

\author{
Thuan Minh Huynh ${ }^{1,2 *}$, Udo Armbruster ${ }^{1}$, Luong Huu Nguyen², Duc Anh Nguyen², \\ Andreas Martin ${ }^{1^{*}}$ \\ ${ }^{1}$ Leibniz Institute for Catalysis at University of Rostock, Rostock, Germany \\ ${ }^{2}$ Vietnam Petroleum Institute, Hanoi, Vietnam \\ Email: "thuan.huynh@catalysis.de, "andreas.martin@catalysis.de
}

Received 9 October 2015; accepted 24 November 2015; published 27 November 2015

Copyright (C 2015 by authors and Scientific Research Publishing Inc.

This work is licensed under the Creative Commons Attribution International License (CC BY). http://creativecommons.org/licenses/by/4.0/

CC) (i) Open Access

\section{Abstract}

Two series of bimetallic Ni-Co catalysts and corresponding monometallic catalysts with ca. 20 wt\% metal loading were evaluated in hydrodeoxygenation (HDO) of phenol as a model compound for bio-oil. The bimetallic catalysts outperformed the corresponding monometallic catalyst in terms of conversion and cyclohexane selectivity. This could be attributed to the formation of Ni-Co alloy, which caused a decrease in metal particle size and stabilized Ni active sites in the near surface region. The balanced combination of formed Ni-Co alloy with acidity from supports allowed performing all individual steps in the reaction network toward desired products at high rate. Consequently, the two best-performing catalysts were tested in HDO of wood based bio-oil, showing that the bimetallic catalyst 10Ni10Co/HZSM-5 was more effective than 20Ni/HZSM-5 in terms of degree of deoxygenation and upgraded bio-oil yield. These findings might open an opportunity for development of a novel cheap but effective catalyst for a key step in the process chain from biomass to renewable liquid fuels.

\section{Keywords}

Bimetallic Catalysts, Hydrodeoxygenation, Phenol, Bio-Oil, Ni-Co Alloy

\section{Introduction}

Energy and environmental issues are two common concerns of modern society. Worldwide energy consumption

\footnotetext{
${ }^{*}$ Corresponding authors.
}

How to cite this paper: Huynh, T.M., Armbruster, U., Nguyen, L.H., Nguyen, D.A. and Martin, A. (2015) Hydrodeoxygenation of Bio-Oil on Bimetallic Catalysts: From Model Compound to Real Feed. Journal of Sustainable Bioenergy Systems, 5, 151-160. http://dx.doi.org/10.4236/jsbs.2015.54014 
increased rapidly from 10.6 to 12.9 billion tons of oil equivalent during the last decade. Fossil fuels based energy resources, including coal, gas and oil, supplied the vast majority (86\%) of the total world energy demand in 2014 [1]. Consequently, the emission of greenhouse gas to the atmosphere, especially the amount of $\mathrm{CO}_{2}$ emission, grew by 22\% from 29.1 (2004) to 35.5 billion tons (2014) [1]. This contributes to global warming and probably increases the number of natural disasters. To encounter these threats, the utilization of non-conventional sources (e.g. wind, sunlight, and biofuels) is required. The currently preferred route bases on the use of so-called $1^{\text {st }}$ generation biofuels (e.g. bioethanol, biodiesel) to replace partly conventional liquid fuels (gasoline, diesel) in the transportation sector (e.g. for light vehicles, trucks).

Nevertheless, the use of biofuels is still under debate owing to the competitive use as food and edible oils. Therefore, the focus of research nowadays shifts to the use of waste biomass thanks to its abundant availability, sustainability and $\mathrm{CO}_{2}$-neutrality. Therefrom derived fuels are discussed as $2^{\text {nd }}$ generation biofuels. However, the biggest challenges for the large-scale implementation of renewable fuels from biomass are its low volumetric and energy densities, pointing to high costs for harvesting and transportation. In the light of that, liquefaction and fast pyrolysis appear as promising technologies, which transform biomass into a liquid so-called bio-oil with high energy density compared to original biomass [2]. Liquefaction processes have been developed since the 1920s following a concept of oil production directly from wet biomass with or without catalysts; however, they run under hydrothermal conditions at high pressure (ca. 200 bar) which result in some technical difficulties and high capital costs. Meanwhile, fast pyrolysis (FP) has developed since late 1970s and seems to be a promising technology. This process runs at atmospheric pressure or lower in the absence of oxygen with short residence time (1 - $2 \mathrm{~s}$ ) in a typical temperature range of $450^{\circ} \mathrm{C}-550^{\circ} \mathrm{C}$, and the obtained bio-oil covers up to $80 \%$ carbon yield on dry basis [3]-[5].

However, the biggest drawback of bio-oil is its quality being far away from conventional liquid fuels due to high oxygenates and water contents, originating from the nature of biomass [6]. Remarkably, more than 200 oxygenated compounds in bio-oils are known, having various types of functional groups (e.g. acids, alcohols, phenols, sugars, aldehydes, ketones and esters) with specific chemistry. Their concentrations depend on the nature of biomass feed and the pyrolysis conditions, and detection and quantification in the bio-oils are challenging up to now [7] [8].

The high oxygenates content in bio-oil obtained from FP process (35 - $40 \mathrm{wt} \%$ on dry basis) causes some undesired features such as immiscibility with conventional fuels, high viscosity, low volatility, corrosivity and instability during long-time storage. In addition, the water content accounts to 15 - $30 \mathrm{wt} \%$, bound as an emulsion, and it is not easy to separate by conventional methods. Therefore, it is necessary to lower the oxygen content to upgrade the quality of bio-oil and ultimately to make it suitable as a fuel component. For this purpose, hydrodeoxygenation (HDO), which is performed under elevated hydrogen pressure at moderate or high temperature $\left(200^{\circ} \mathrm{C}-450^{\circ} \mathrm{C}\right)$ in presence of a heterogeneous catalyst, has been intensively studied.

Variety of catalysts has been developed and tested for HDO of bio-oil and related model compounds, as recently reviewed in detail [9] [10]. To take advantage of mature technologies for removal of heteroatoms in conventional petroleum refinery, the same catalysts and conditions as applied in hydrodesulfurization (HDS; sulfided $\mathrm{Ni}-\mathrm{Mo} / \mathrm{Al}_{2} \mathrm{O}_{3}$ and $\mathrm{Co}-\mathrm{Mo} / \mathrm{Al}_{2} \mathrm{O}_{3}$ ) and hydrotreating (supported noble metals $\mathrm{Pt}, \mathrm{Pd}, \mathrm{Ru}, \mathrm{Rh}$ ) processes we retransferred to bio-oil HDO because the tasks are similar. However, HDS catalysts deactivated quickly due to loss of sulfur and the sulfur concentration in bio-oil being too low for their reactivation [11] [12]. Additionally, the conventional support $\mathrm{Al}_{2} \mathrm{O}_{3}$ is not stable at HDS conditions in presence of the high amount of water in bio-oil. Meanwhile, hydrotreatment catalysts show higher activity than conventional HDS catalysts [13]-[16]. Such precious metal catalysts are, however, more expensive than HDS catalysts and their resources are limited.

Non-noble monometallic catalysts (e.g. supported $\mathrm{Ni}$, Fe, and $\mathrm{Cu}$ catalysts) have already been investigated in HDO studies [17]-[20]. However, catalyst deactivation is still a problem due to coke deposition and metal leaching into water [19] [20]. Few groups also reported on bimetallic catalysts (e.g. Pt-Fe/C, Pt-Cu/SiO 2 , Ni-Cu/ $\delta$ - $\mathrm{Al}_{2} \mathrm{O}_{3}, \mathrm{Ni}-\mathrm{Fe} / \mathrm{Al}_{2} \mathrm{O}_{3}$ ) for HDO of bio-oil and related model compounds [21]-[24]. Nonetheless, the price of the precious metal catalysts and the stability of supports under hydrothermal environment rule out the application. This indicates that further catalyst development is needed to realize economic alternative formulation and to overcome the indicated drawbacks.

It should be noted that the combination of metallic and acidic sites in suitable catalysts seems to be essential for HDO reaction to catalyze all the elementary steps in the preferred deoxygenation pathways. In addition, the catalyst material should be resistant to coking and heteroatoms in bio-oil in order to increase the catalyst lifetime. 
For this purpose, we have recently studied bimetallic Ni-Co and Ni-Cu-containing catalysts using HZSM-5 as carrier for aqueous phase HDO of phenol as a model compound for bio-oil to overcome the discussed drawbacks [25]. From these previous studies, a $10 \mathrm{wt} \% \mathrm{Ni}+10 \mathrm{wt} \%$ Co supported on HZSM- 5 catalyst revealed best performance [25]. In this continuative study, two series of monometallic (Ni) and bimetallic ( $\mathrm{Ni}+\mathrm{Co})$ catalysts supported on acidic carriers (HZSM-5, HBeta, $\mathrm{HY}$ and $\mathrm{ZrO}_{2}$ ) were evaluated in phenol HDO to discover the impact of support and the reaction pathways. The transfer from the model reaction to conversion of bio-oil was performed afterwards with the best-performing catalysts to shed some light on the catalyst performance in real feed and the comparability of model and real reactions.

\section{Experimental Procedures}

\subsection{Catalyst Preparation}

Two series of monometallic and bimetallic catalysts with ca. $20 \mathrm{wt} \%$ metal loading were prepared by incipient wetness impregnation and co-impregnation methods, respectively. A detailed description of catalyst preparation procedures is available elsewhere [25]. Herein, four acidic supports were used, namely HZSM-5 (PZ-2/25H, Zeochem AG), HBeta (PB/H, Zeochem AG), HY derived from $\mathrm{NH}_{4} \mathrm{Y}$ (CBV712, Zeolyst) and $\mathrm{ZrO}_{2}$ (Saint Gobain). Before catalyst synthesis, $\mathrm{NH}_{4} \mathrm{Y}$ was calcined at $550^{\circ} \mathrm{C}$ to get corresponding $\mathrm{HY}$ form, whereas other supports were calcined at $450^{\circ} \mathrm{C}$ for $2 \mathrm{~h}$ to remove physisorbed water. $\mathrm{Ni}\left(\mathrm{NO}_{3}\right)_{2} \cdot 6 \mathrm{H}_{2} \mathrm{O}$ (Merck) and $\mathrm{Co}\left(\mathrm{NO}_{3}\right)_{2} \cdot 6 \mathrm{H}_{2} \mathrm{O}$ (Fluka) were used as precursors for $\mathrm{Ni}$ and $\mathrm{Co}$, respectively.

\subsection{Catalyst Characterization}

The physico-chemical methods used for catalyst characterization are presented in the following short summary. Detailed information is also described in our previous study [25].

Nitrogen physisorption measurements were performed on a Micromeritics ASAP 2010 apparatus at $-196^{\circ} \mathrm{C}$. Prior to analysis, the calcined solids were degassed at $200^{\circ} \mathrm{C}$ in vacuum for $4 \mathrm{~h}$.

$\mathrm{X}$-ray powder diffraction (XRD) measurements used for the phase composition study were performed by using a theta/theta diffractometer (X'Pert Pro from Panalytical, Almelo) with CuK $\alpha$ radiation ( $\lambda=0.15418 \mathrm{~nm}, 40$ $\mathrm{kV}, 40 \mathrm{~mA}$ ) and a X'Celerator RTMS Detector. Crystallite size was calculated by the Scherrer equation.

Acidic properties were determined by pyridine IR measurements in transmission mode on a Bruker Tensor 27 spectrometer. The pre-reduced catalysts were pretreated in $5 \% \mathrm{H}_{2} / \mathrm{He}$ at $400^{\circ} \mathrm{C}$ for $10 \mathrm{~min}$. After cooling to RT and evacuation, the pyridine adsorption was performed until saturation. Then, the reaction cell was evacuated to remove physisorbed pyridine and finally the desorption of pyridine was followed by heating the sample in vacuum up to $300^{\circ} \mathrm{C}$ and recording spectra every $50 \mathrm{~K}$.

\subsection{Activity Tests}

HDO of phenol as a model compound was carried out in an autoclave (Parr Instruments, $25 \mathrm{ml}$ ).Typically, phenol $(0.5 \mathrm{~g}), \mathrm{H}_{2} \mathrm{O}(10 \mathrm{~g})$, and catalyst $(0.025 \mathrm{~g})$ were placed into the reactor. Argon was used to remove air and then the autoclave was pressurized with $\mathrm{H}_{2}$ to 50 bar at RT. The start time was recorded when the temperature reached $250^{\circ} \mathrm{C}$ and then stirring speed was set to $650 \mathrm{rpm}$. After cooling to RT, the product gas was analyzed by gas chromatography (GC, HP 5890) online from autoclave. The liquid products (organic and aqueous phase) were analyzed by another GC (Shimadzu 17A) with autosampler. The internal standards mesitylene and 1,4-dioxane were used for quantification of organic and aqueous phases, respectively. Conversion and selectivity were calculated based on the following equations:

$$
\begin{gathered}
\text { Conversion }=\frac{\text { moles of phenol }(\text { initial })-\text { moles of phenol }(\text { final })}{\text { moles of phenol }(\text { initial })} \times 100 \% \\
\text { Selectivity }=\frac{\text { moles of carbon atoms in each product }}{\text { total moles of carbon atoms in the products }} \times 100 \%
\end{gathered}
$$

The carbon balances were calculated from the detected products and reached more than $90 \%$ in this work. Missing carbon was due to mostly work-up procedure (e.g. extraction step), deposits on the surface of catalysts and some unknown minor peaks in chromatograms. 
HDO of bio-oil was performed in another autoclave (Parr Instruments, $100 \mathrm{ml}$ ). Typically, bio-oil and catalyst were placed into the autoclave. The reactor was flushed with $\mathrm{N}_{2}$ to remove air and subsequently pressurized to 60 bar $\mathrm{H}_{2}$ at RT. The reactor was heated to desired temperature and the starting time $(\mathrm{t}=0)$ was recorded as the stirring speed was set to $650 \mathrm{rpm}$. After completing the reaction, the gas phase was analyzed by a GC (Agilent 7890). Dichloromethane (DCM) was used to extract the organic phase and the resulting solution was evaporated to remove DCM and finally an upgraded bio-oil (UBO) was obtained. The amounts of UBO, aqueous phase, gas phase and char were determined experimentally and the product yields were calculated on wet basis by following equation.

$$
\text { Yield }(w t \%)=\frac{m_{\text {product }}}{m_{\text {feed }}} \times 100 \%
$$

Water content and $\mathrm{pH}$ of the original bio-oil were measured by a Karl-Fischer-titration (MKS-520 Mettler Toledo) and an UB-10 pH/mV/Temp (Denver Instrument), respectively. Elemental compositions (C, H, N) of the parent bio-oil and UBO were carried out on a CHN/CHNS Vario Macro analyzer according to ASTM D5291-10. Subsequently, the dry elemental compositions were calculated and then the oxygen content was calculated by difference. Degree of deoxygenation (DOD) and the higher heating value (HHV) using Dulong's formula were calculated by the following equations.

$$
\begin{gathered}
\operatorname{DOD}(\%)=\frac{\% \mathrm{O}(\text { bio-oil })-\% \mathrm{O}(\mathrm{UBO})}{\% \mathrm{O}(\text { bio-oil })} \times 100 \% \\
\mathrm{HHV}(\mathrm{MJ} / \mathrm{kg})=\left[338.2 \% \mathrm{C}+1442.8\left(\% \mathrm{H}-\frac{\% \mathrm{O}}{8}\right)\right] \times 0.001
\end{gathered}
$$

The coke deposited on spent catalyst was determined by a CHN analyzer (LECO-CS600).

\section{Results and Discussion}

\subsection{Fresh Catalyst Characterization}

The catalyst samples have been denoted as $\mathrm{xNiyCo} / \mathrm{Z}$, where $\mathrm{Z}$ is the name of support and $\mathrm{x}$ and $\mathrm{y}$ are the contents (wt\%) of nickel and cobalt, respectively. Table 1 summarizes physico-chemical properties of prepared catalysts, some of them are stemming from our previous studies [25] [26]. In fact, the surface areas followed the support order: HY $>$ HBeta $>\mathrm{HZSM}-5>\mathrm{ZrO}_{2}$. It should be noted that the surface area of monometallic and bimetallic catalysts with the same support are similar, thus the discrimination of performance of those catalyst couples could be related to structure, particle size or acidity rather than to surface area.

The XRD patterns of the HZSM-5 and HBeta supported pre-reduced catalysts were discussed elsewhere [25] [26]. It was highlighted that the reflections for the metallic particles occurred between known reflections of me-

\begin{tabular}{|c|c|c|c|c|c|}
\hline \multirow{2}{*}{ Samples $^{\mathrm{a}}$} & \multirow{2}{*}{ Surface area $\left(\mathrm{m}^{2} / \mathrm{g}\right)$} & \multirow{2}{*}{ Crystallite size (nm) } & \multicolumn{3}{|c|}{ Acidity ( $\mu \mathrm{mol} / \mathrm{g})$} \\
\hline & & & Brønsted & Lewis & Total \\
\hline $20 \mathrm{Ni} / \mathrm{ZrO}_{2}$ & 29 & $\mathrm{n} / \mathrm{d}$ & $\mathrm{n} / \mathrm{d}$ & $\mathrm{n} / \mathrm{d}$ & $\mathrm{n} / \mathrm{d}$ \\
\hline $10 \mathrm{Ni} 10 \mathrm{Co} / \mathrm{ZrO}_{2}$ & 40 & 29.8 & 0 & 44 & 44 \\
\hline $20 \mathrm{Ni} / \mathrm{HY}$ & 540 & $\mathrm{n} / \mathrm{d}$ & $\mathrm{n} / \mathrm{d}$ & $\mathrm{n} / \mathrm{d}$ & $\mathrm{n} / \mathrm{d}$ \\
\hline 10Ni10Co/HY & 568 & 23.3 & 259 & 505 & 765 \\
\hline 20Ni/HBeta ${ }^{\mathrm{b}}$ & 443 & $\mathrm{n} / \mathrm{d}$ & 187 & 870 & 1.057 \\
\hline 10Ni10Co/HBeta ${ }^{\mathrm{b}}$ & 443 & 19.0 & 137 & 984 & 1.121 \\
\hline $20 \mathrm{Ni} / \mathrm{HZSM}-5^{\mathrm{c}}$ & 281 & 29.7 & 243 & 345 & 588 \\
\hline 10Ni10Co/HZSM-5 ${ }^{\mathrm{c}}$ & 281 & 15.1 & 162 & 509 & 672 \\
\hline
\end{tabular}
tallic Ni and Co, pointing to the formation of Ni-Co alloy, which was confirmed by images obtained from trans-

Table 1. Physico-chemical properties of fresh pre-calcined catalysts.

${ }^{\mathrm{a}} \mathrm{n} / \mathrm{d}$ : not determined, ${ }^{\mathrm{b}}$ Acidity data from [26], ${ }^{\mathrm{c}}$ Acidity data from [25]. 
mission electron microscopy (TEM) studies. This effect was observed also for the other bimetallic catalysts used in this study. The acidities of the pre-reduced catalysts are presented in Table 1 including some data for HZSM5 and HBeta based samples [25] [26]. It should be noted that with the same support (as measured for HZSM-5 or HBeta), the number of Brønsted acid sites in monometallic catalysts was higher than in bimetallic catalysts, whereas the Lewis acid sites showed the reverse trend, probably due to the difference in valence states of Ni and Co [26]. The Brønsted acid sites in bimetallic catalysts follow the order $\mathrm{HY}>\mathrm{HZSM}-5>\mathrm{HBeta}>\mathrm{ZrO}_{2}$. When being normalized to surface area, the Brønsted acid site densities display another trend HZSM-5 > HY > HBeta > $\mathrm{ZrO}_{2}$, pointing to the high Brønsted site density of HZSM-5.

\subsection{HDO of Phenol as a Model Compound}

In previous study, we observed that bimetallic Ni-Co/HZSM-5 outperformed monometallic catalysts and Ni-Cu/ HZSM-5 series in terms of phenol conversion, cyclohexane selectivity and coke deposition [25]. Herein, two se-

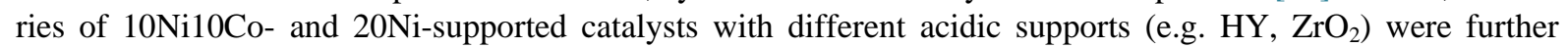
checked in the present study. The HDO results using the pre-reduced catalysts at the same reaction conditions ( $0.5 \mathrm{~g}$ of phenol, $10 \mathrm{~g}$ of $\mathrm{H}_{2} \mathrm{O}, 25 \mathrm{mg}$ of catalyst, $\mathrm{T}=250^{\circ} \mathrm{C}, \mathrm{p}=50 \mathrm{bar}_{2}$ at RT, t $=2 \mathrm{~h}$ ) are depicted in Figure 1. Some of the data from previous studies also presented here for comparison.

Phenol HDO leads to oxygenated (cyclohexanol, cyclohexanone) and deoxygenated products (cyclohexane, cyclohexene, benzene, and methylcyclopentane (MCP)). The reaction pathways are depicted in Figure 2. Notably, all bimetallic catalysts (10Ni10Co/Z) outperformed the corresponding monometallic catalysts $(20 \mathrm{Ni} / \mathrm{Z})$ in terms of phenol conversion and selectivity toward deoxygenated products, independent from used support. This indicates the benefit of addition of Co to Ni catalysts.

Regarding the bimetallic catalysts, the phenol conversion reached $100 \%$ for $10 \mathrm{Ni} 10 \mathrm{Co} / \mathrm{ZrO}_{2}$ despite its comparatively low BET surface area, whereas the values for HZSM-5, HBeta and HY supported samples reached $100 \%, 85 \%$ and $36 \%$, respectively. On the other side, also the related product distributions differed significantly from each other. Selectivity toward deoxygenated products reached ca. $10 \%$ for $10 \mathrm{Ni} 10 \mathrm{Co} / \mathrm{ZrO}_{2}$, whereas almost $100 \%$ were achieved with $10 \mathrm{Ni10Co/HZSM}-5$. Intermediate values of $84 \%$ and $30 \%$ were obtained for 10Ni10Co/HBeta and 10Ni10Co/HY, respectively.

The high yields toward hydrocarbon on 10Ni10Co/HZSM-5 can be attributed to the additional high density of Brønsted acid sites introduced by the support (Table 1). As soon as metal and acid sites are present at the same time, all desired steps are catalyzed with significant rates. However, the obtained selectivities to deoxygenated

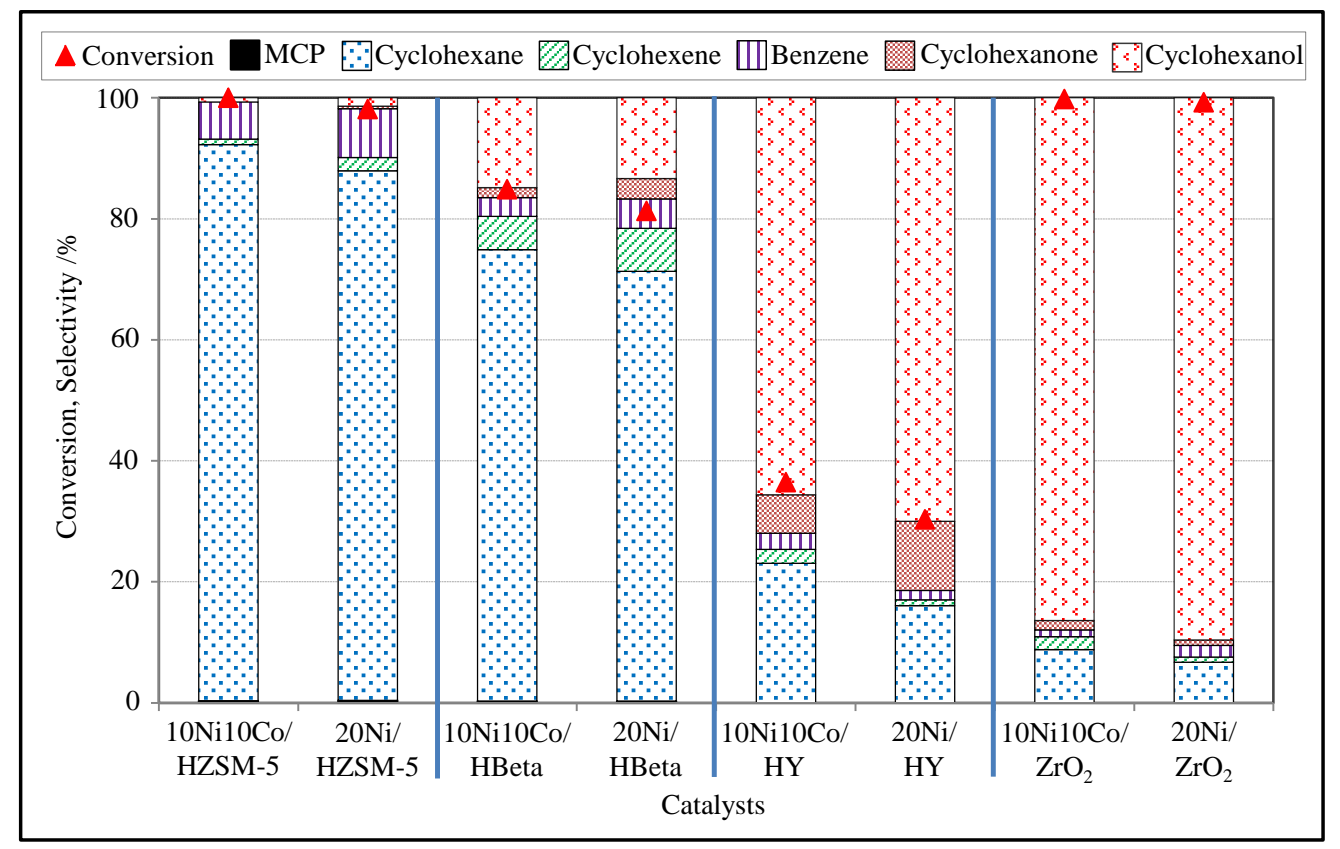

Figure 1. Results from phenol HDO on supported monometallic and bimetallic catalysts. 


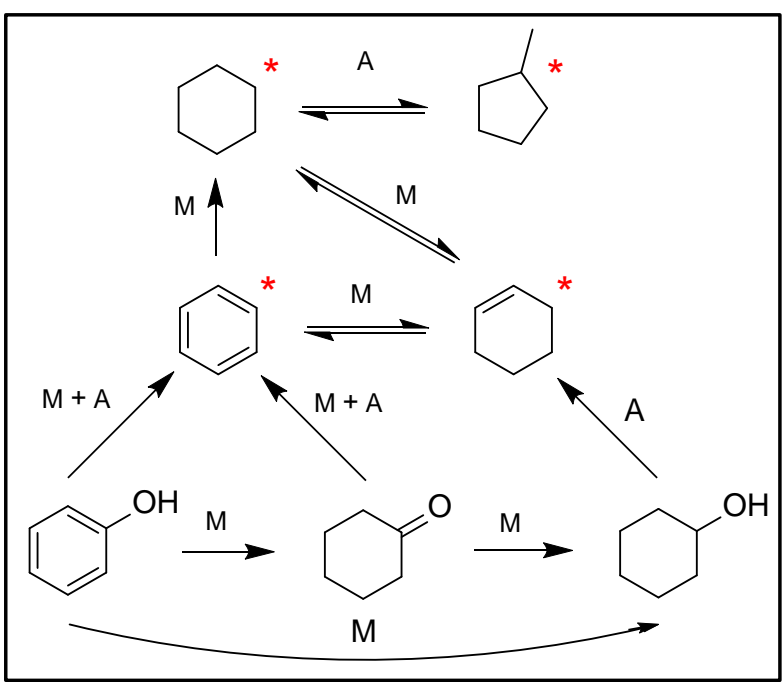

Figure 2. Proposed reaction pathway of phenol HDO over supported Ni based catalysts ( $\mathrm{M}=$ metal/alloy sites, $\mathrm{A}=$ acidic sites, asterisks mark deoxygenated products).

products deviate from the above presented order of Brønsted acid site densities of the supports. With second ranking $10 \mathrm{Ni} 10 \mathrm{Co} / \mathrm{HY}$, the selectivity toward hydrocarbon reached only $30 \%$, though this catalyst also possessed high acid density. The comparatively low phenol conversion as well as the poor HDO selectivity can be assigned to the collapse of zeolite Y structure [27], diminishing the number of available Brønsted acid sites, which are crucial to promote the consecutive steps in the $\mathrm{HDO}$ reaction network. On the other side, $10 \mathrm{Ni} 10 \mathrm{Co} / \mathrm{ZrO}{ }_{2}$ is only active in hydrogenation (Figure 2) promoted by the metal sites, but is not able to dehydrate cyclohexanol to cyclohexene under given conditions because $\mathrm{ZrO}_{2}$ lacks acidity. Thus, the consecutive reaction stops after the first step as discussed below in Figure 2.

Based on above described experiments combined with results from HDO of the observed intermediates as individual feeds as shown in previous study [25], the reaction network is proposed as shown in Figure 2. In general, two main reaction routes were observed with the investigated catalysts. This is confirmed by the presence of benzene (DDO route), cyclohexanone and cyclohexanol (HYD route) in the products. The latter product was further dehydrated to form cyclohexene and finally hydrogenated to cyclohexane. Methylcyclopentane (MCP) only occurred with zeolite supported catalysts via the isomerization of cyclohexane in the presence of Brønsted acid sites. The results from HDO of intermediate products indicate that benzene also formed via dehydrogenation of cyclohexene. This might be assigned to the ability of $\mathrm{Ni}$ to act also as a dehydrogenation catalyst. However, dehydrogenation gets first relevant above $250^{\circ} \mathrm{C}$, whereas appearance of benzene at low temperature rather points to the reaction along the DDO route.

The proposed pathways are supported by findings of Zhang et al. [19] and Hong et al. [14] with two main routes. In contrast, Zhao et al. [28] proposed that hydrogenolysis of phenol to benzene as well as hydrogenolysis of cyclohexanol to cyclohexane are running scarcely when using carbon-supported noble metal catalyst $(\mathrm{Pt} / \mathrm{C}$, $\mathrm{Ru} / \mathrm{C}, \mathrm{Pd} / \mathrm{C})$ and a mineral acid at the given reaction conditions $\left(200^{\circ} \mathrm{C}, 50\right.$ bar $\mathrm{H}_{2}$ at $\left.\mathrm{RT}\right)$. The same group reported that benzene did not form in phenol HDO using Ni/HZSM-5 and Ni/ $\mathrm{Al}_{2} \mathrm{O}_{3}-\mathrm{HZSM}-5$ at the same conditions $\left(200^{\circ} \mathrm{C}, 50 \mathrm{bar}_{2}\right.$ at RT) [20]. This clearly indicates that hydrogenation is thermodynamically favorable at low temperature and promotes the HYD route. Anyway, it is well known that several parameters (e.g., temperature, pressure, solvent) and reaction environment (aqueous or gas phase) play an important role for the selection of the preferred pathways [29].

\subsection{HDO of Bio-Oil}

The bio-oil used in this study was produced by fast pyrolysis of wood (PYTEC GmbH) by the hot rotating disk technique. Typically, bio-oil represents a complex mixture of hundreds of chemical compounds. Table 2 summarizes some typical properties of the bio-oil compared to fossil heavy fuel oil [30]. Obviously, bio-oil has significantly higher oxygen and water contents and roughly half of higher heating value (HHV) compared to the 
heavy fuel oil. With phenol as a model compound as shown above, the classical parameters conversion and selectivity were used for catalyst evaluation. However, these parameters are not accessible for the evaluation of bio-oil HDO due to the complexity of the original feed and because the exact molecular composition is unknown. Instead, easily accessible sum parameters like the product yields per weight or DOD value (specific change in oxygen content) together with a van Krevelen plot, which displays the $\mathrm{O}: \mathrm{C}$ and $\mathrm{H}$ : $\mathrm{C}$ molar ratios as a measure of fuel quality, are common tools for catalyst evaluation in bio-oil HDO.

The optimum batch-operating HDO conditions ( $5 \mathrm{~g}$ of bio-oil, $25 \mathrm{~g}$ of $\mathrm{H}_{2} \mathrm{O}, 1 \mathrm{~g}$ of catalyst, $\mathrm{p}=60 \mathrm{bar}_{2}$ at $\mathrm{RT}, \mathrm{T}=300^{\circ} \mathrm{C}, \mathrm{t}=4 \mathrm{~h}$ ) were applied in this study based on our previous investigation. The obtained product is furthermore denoted as upgraded bio-oil (UBO). The yields for the various product phases and the DOD are shown in Table 3. It should be noted that the work-up procedure and the evaporation of DCM solvent caused a loss in the mass balance of about 9 - $11 \mathrm{wt} \%$.

Obviously, the UBO yield obtained with 10Ni10Co/HZSM-5 was slightly higher than that obtained with 20Ni/HZSM-5, whereas the fraction of products in the aqueous phase was comparable. This is in line with the higher percentage of gas phase which was produced with monometallic catalyst (roughly $20 \mathrm{wt} \%$ ) than with bimetallic catalyst (15 wt\%). This can be attributed to the higher number of Brønsted acid sites in monometallic catalyst compared to bimetallic catalyst (see Table 1). The main components in the gas phase were the remaining $\mathrm{H}_{2}$, methane, $\mathrm{CO}_{2}$, and various gaseous hydrocarbons $\left(\mathrm{C}_{2}\right.$ to $\left.\mathrm{C}_{4+}\right)$ (not shown here). Compared to the model reaction with phenol, $\mathrm{CO}_{2}$ and $\mathrm{CO}$ were now observed in these tests due to the presence of several functional groups (e.g. carboxylic acids, aldehydes) in the starting feed which are prone to decarboxylation and decarbonylation, respectively.

In addition to the higher UBO yield, the bimetallic catalyst also showed a higher activity for oxygen elimination than the monometallic catalyst as reflected by the DOD value. As the number of acid sites is less for the bimetallic catalyst, this must be a particular feature of the metal sites. The dispersion of Ni active sites is higher, and additionally smaller crystallites were formed by substituting Ni with Co (see Table 1); this is backed by XRD and TEM data from previous study [25]. It seems that the interplay of acid and metal sites is better balanced than in monometallic catalyst. Another explanation could be attributed to the larger extent of coke formation as determined by elemental analyzer (see Table 3) and the hard coke formation as indicated by TPO result (not shown here) in 20Ni/HZSM-5, which is known to increase with the acid strength of the catalyst, in general. This possibly affects the availability of active sites and lowers catalyst activity and selectivity. Finally, the molar O:C ratio of the UBO with 10Ni10Co/HZSM-5 (0.26) was considerably lower, whereas the molar H:C ratio (1.91) was higher compared to those obtained from original bio-oil (O:C 0.51, $\mathrm{H}: \mathrm{C} \sim 1.5$ ), indicating an effective HDO reaction (see Figure 3). Compared with fossil liquid fuels, the molar $\mathrm{H}$ : $\mathrm{C}$ ratio of the UBO obtained

Table 2. Typical properties of bio-oil vs. heavy fuel oil.

\begin{tabular}{ccccc}
\hline & Properties & & Bio-oil & Heavy fuel oil $^{\text {a }}$ \\
\hline \multirow{2}{*}{ Wet basis } & $\mathrm{H}_{2} \mathrm{O}(\mathrm{wt} \%)$ & 32.6 & 0.1 \\
& $\mathrm{pH}$ & 3.2 & 85 \\
\hline \multirow{2}{*}{ Dry basis, wt\% } & $\mathrm{C}$ & 55.3 & 11 \\
& $\mathrm{H}$ & 6.9 & 0.3 \\
\hline $\mathrm{HHV}(\mathrm{MJ} / \mathrm{kg})$ & $\mathrm{N}$ & 0.3 & 1.0 \\
\hline
\end{tabular}

${ }^{\mathrm{a}}$ Data obtained from reference [30].

Table 3. Performance of HZSM-5 supported catalysts in bio-oil HDO.

\begin{tabular}{|c|c|c|c|c|c|c|c|c|c|c|c|c|}
\hline \multirow{2}{*}{ Samples $^{\mathrm{a}}$} & \multicolumn{5}{|c|}{ Yield (wt\%) } & \multicolumn{4}{|c|}{ Elemental composition (dry basis) } & \multirow{2}{*}{$\begin{array}{c}\text { DOD } \\
(\%) \\
\end{array}$} & \multirow{2}{*}{$\begin{array}{c}\text { HHV } \\
(\mathrm{MJ} / \mathrm{kg})\end{array}$} & \multirow{2}{*}{$\begin{array}{c}\text { Coke deposits } \\
\text { (wt\%) }\end{array}$} \\
\hline & UBO & AQ & Gas & Char & Loss & $\mathrm{C}$ & $\mathrm{H}$ & $\mathrm{N}$ & $\mathrm{O}$ & & & \\
\hline Bio-oil & - & - & - & - & - & 55.3 & 6.9 & 0.3 & 37.4 & - & 21.9 & \\
\hline 20Ni/HZSM-5 & 32.3 & 35.6 & 20.4 & 2.5 & 9.2 & 62.6 & 8.9 & 0.23 & 28.2 & 25 & 29.0 & 6.5 \\
\hline 10Ni10Co/HZSM-5 & 36.7 & 35.3 & 14.6 & 2.0 & 11.3 & 66.4 & 10.6 & 0.26 & 22.8 & 39 & 33.6 & 4.8 \\
\hline
\end{tabular}

${ }^{\mathrm{a}} \mathrm{UBO}=$ upgraded bio-oil, $\mathrm{AQ}=$ aqueous phase, $\mathrm{Gas}=$ gas phase, $\mathrm{DOD}=$ degree of deoxygenation, $\mathrm{HHV}=$ higher heating value. 


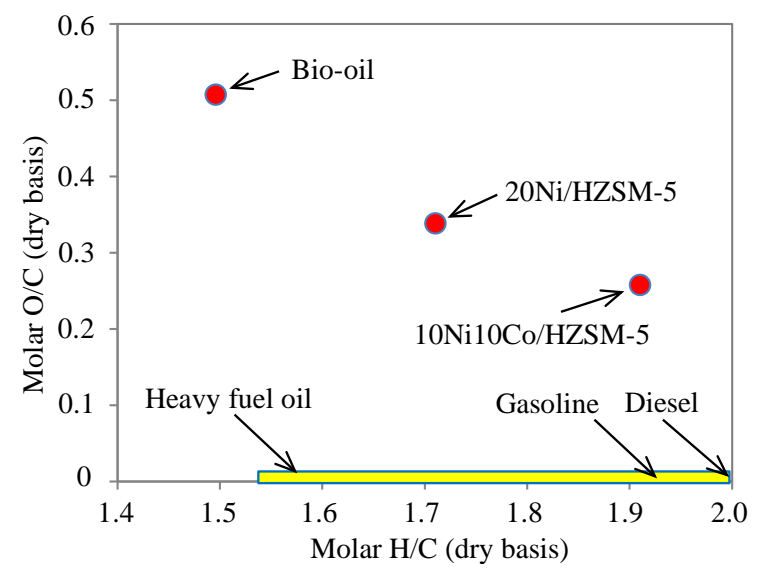

Figure 3. van Krevelen plot for bio-oil, UBOs and fossil liquid fuels.

with 10Ni10Co/HZSM-5 was much higher than that of conventional heavy fuel oil and comparable to those of gasoline and diesel, whereas the O: C ratio was relatively higher, as expected. As a result, a direct use of such HDO product as a fuel component still is no option because of residual O: $\mathrm{C}$ ratio; however, it might be suited as a co-feed for standard refinery unit (e.g. fluid catalytic cracking, hydrotreating).

The highest oil yield on wet basis (37 wt\%) together with highest DOD (39\%) were achieved with the bimetallic catalyst (10Ni10Co/HZSM-5) under the investigated conditions.

\section{Summary}

This study presents results from aqueous phase HDO over various supported transition metal-containing catalysts with phenol as a model compound for screening purpose. The supports determine the surface area of the catalyst and introduce acidity into the catalyst, which is necessary to perform the dehydration steps in the reaction network. It must be pronounced that the hydrothermal stability of support plays an important role in catalyst performance, too. Among investigated supports, HZSM-5 was the best due to its high acidity in combination with hydrothermal stability in aqueous environment. In addition, various HDO tests were carried out using a bio-oil obtained from flash pyrolysis of wood and the same catalysts in batch mode.

The tests with HZSM-5 supported catalysts revealed that bimetallic 10Ni10Co/HZSM-5 exhibited significantly higher efficiency compared to monometallic 20Ni/HZSM-5 in terms of degree of deoxygenation and UBO yield. The substitution of Co with Ni leads to formation of Ni-Co alloy with better stabilized Ni domains found in better dispersed metal crystallites on the catalyst surface. Compared to monometallic catalyst, the balance is slightly shifted towards more effective metal sites, whereas the acid sites are slightly less, and this gives a better balance of the metal and acid sites in the bimetallic catalyst. These conditions not only catalyzed all individual reactions toward desired products but also decreased the amount of coke deposits on the surface of catalyst and improved catalyst performance. This finding might offer a new catalyst formulation with cheap materials but effective for HDO of bio-oil.

\section{Acknowledgements}

The authors want to thank Dr. M. Schneider, Dr. U. Bentrup and Ms. A. Lehmann (all at LIKAT) for analytical support. Financial support by the Vietnam Oil and Gas Group (Petrovietnam) and LIKAT is gratefully acknowledged.

\section{References}

[1] (2015) BP Statistical Review of World Energy. www.bp.com/en/global/corporate/about-bp/energy-economics/statistical-review-of-world-energy.html

[2] Mohan, D., Pittman, C.U. and Steele, P.H. (2006) Pyrolysis of Wood/Biomass for Bio-Oil: A Critical Review. Energy Fuels, 20, 848-889. http://dx.doi.org/10.1021/ef0502397

[3] Bridgwater A.V. and Peacocke G.V.C. (2000) Fast Pyrolysis Processes for Biomass. Renewable \& Sustainable Energy 
Reviews, 4, 1-73. http://dx.doi.org/10.1016/S1364-0321(99)00007-6

[4] Meier, D., van de Beld, B., Bridgwater, A.V., Elliott, D.C., Oasmaa, A. and Preto, F. (2013) State-of-the-Art of Fast Pyrolysis in IEA Bioenergy Member Countries. Renewable \& Sustainable Energy Reviews, 20, 619-641. http://dx.doi.org/10.1016/j.rser.2012.11.061

[5] Bridgwater, A.V. (2012) Review of Fast Pyrolysis of Biomass and Product Upgrading. Biomass Bioenergy, 38, 68-94. http://dx.doi.org/10.1016/j.biombioe.2011.01.048

[6] Mortensen, P.M., Grunwaldt, J.D., Jensen, P.A., Knudsen, K.G. and Jensen, A.D. (2011) A Review of Catalytic Upgrading of Bio-Oil to Engine Fuels. Applied Catalysis A, 407, 1-19. http://dx.doi.org/10.1016/j.apcata.2011.08.046

[7] Elliott, D.C., Biller, P., Ross, A.B., Schmidt, A.J. and Jones, S.B. (2015) Hydrothermal Liquefaction of Biomass: Developments from Batch to Continuous Process. Bioresource Technology, 178, 147-156. http://dx.doi.org/10.1016/j.biortech.2014.09.132

[8] Dahmen, N., Henrich, E., Kruse, A. and Raffelt, K. (2010) Biomass Liquefaction and Gasification. In: Vertès, A.A., Qureshi, N., Blaschek, H.P. and Yukawa, H., Eds., Biomass to Biofuels: Strategies for Global Industries, Wiley, Chichester, 89-122. http://dx.doi.org/10.1002/9780470750025.ch5

[9] Wang, H., Male, J. and Wang, Y. (2013) Recent Advances in Hydrotreating of Pyrolysis Bio-Oil and Its OxygenContaining Model Compounds. ACS Catalysis, 3, 1047-1070. http://dx.doi.org/10.1021/cs400069z

[10] Bu, Q., Lei, H., Zacher, A.H., Wang, L., Ren, S., Liang, J., Wei, Y., Liu, Y., Tang, J., Zhang, Q. and Ruan, R. (2012) A Review of Catalytic Hydrodeoxygenation of Lignin-Derived Phenols from Biomass Pyrolysis. Bioresource Technology, 124, 470-477. http://dx.doi.org/10.1016/j.biortech.2012.08.089

[11] Laurent, E. and Delmon, B. (1994) Influence of Water in the Deactivation of a Sulfided NiMo $\gamma-\mathrm{Al}_{2} \mathrm{O}_{3}$ Catalyst during Hydrodeoxygenation. Journal of Catalysis, 146, 281-291. http://dx.doi.org/10.1016/0021-9517(94)90032-9

[12] Romero, Y., Richard, F. and Brunet, S. (2010) Hydrodeoxygenation of 2-Ethylphenol as a Model Compound of BioCrude over Sulfided Mo-Based Catalysts: Promoting Effect and Reaction Mechanism. Applied Catalysis B: Environmental, 98, 213-223. http://dx.doi.org/10.1016/j.apcatb.2010.05.031

[13] Wildschut, J., Mahfud, F.H., Venderbosch, R.H. and Heeres, H.J. (2009) Hydrotreatment of Fast Pyrolysis Oil Using Heterogeneous Noble-Metal Catalysts. Industrial \& Engineering Chemistry Research, 48, 10324-10334. http://dx.doi.org/10.1021/ie9006003

[14] Hong, D.-Y., Miller, S.J., Agrawal, P.K. and Jones, C.W. (2010) Hydrodeoxygenation and Coupling of Aqueous Phenolics over Bifunctional Zeolite-Supported Metal Catalysts. Chemical Communications, 46, 1038-1040. http://dx.doi.org/10.1039/B918209H

[15] Ohta, H., Kobayashi, H., Hara, K. and Fukuoka, A. (2011) Hydrodeoxygenation of Phenols as Lignin Models under Acid-Free Conditions with Carbon-Supported Platinum Catalysts. Chemical Communications, 47, 12209-12211. http://dx.doi.org/10.1039/c1cc14859a

[16] Ausavasukhi, A., Huang, Y., To, A.T., Sooknoi, T. and Resasco, D.E. (2012) Hydrodeoxygenation of $m$-Cresol over Gallium-Modified Beta Zeolite Catalysts. Journal of Catalysis, 290, 90-100. http://dx.doi.org/10.1016/j.jcat.2012.03.003

[17] Sitthisa, S., Sooknoi, T., Ma, Y., Balbuena, P.B. and Resasco, D.E. (2011) Kinetics and Mechanism of Hydrogenation of Furfural on $\mathrm{Cu} / \mathrm{SiO}_{2}$ Catalysts. Journal of Catalysis, 277, 1-13. http://dx.doi.org/10.1016/j.jcat.2010.10.005

[18] Mortensen, P.M., Grunwaldt, J.-D., Jensen, P.A. and Jensen, A.D. (2013) Screening of Catalysts for Hydrodeoxygenation of Phenol as a Model Compound for Bio-Oil. ACS Catalysis, 3, 1774-1785. http://dx.doi.org/10.1021/cs400266e

[19] Zhang, X., Wang, T., Ma, L., Zhang, Q. and Jiang, T. (2013) Hydrotreatment of Bio-Oil over Ni-Based Catalyst. Bioresource Technology, 127, 306-311. http://dx.doi.org/10.1016/j.biortech.2012.07.119

[20] Zhao, C., Kasakov, S., He, J. and Lercher, J.A. (2012) Comparison of Kinetics, Activity and Stability of Ni/HZSM-5 and $\mathrm{Ni} / \mathrm{Al}_{2} \mathrm{O}_{3}-\mathrm{HZSM}-5$ for Phenol Hydrodeoxygenation. Journal of Catalysis, 296, 12-23. http://dx.doi.org/10.1016/j.jcat.2012.08.017

[21] Ardiyanti, A.R., Khromova, S.A., Venderbosch, R.H., Yakovlev, V.A. and Heeres, H.J. (2012) Catalytic Hydrotreatment of Fast-Pyrolysis Oil Using Non-Sulfided Bimetallic Ni-Cu Catalysts on a $\delta-\mathrm{Al}_{2} \mathrm{O}_{3}$ Support. Applied Catalysis B: Environmental, 117-118, 105-117. http://dx.doi.org/10.1016/j.apcatb.2011.12.032

[22] Sun, J., Karim, A.M., Zhang, H., Kovarik, L., Li, X.S., Hensley, A.J., McEwen, J.-S. and Wang, Y. (2013) CarbonSupported Bimetallic Pd-Fe Catalysts for Vapor-Phase Hydrodeoxygenation of Guaiacol. Journal of Catalysis, 306, 47-57. http://dx.doi.org/10.1016/j.jcat.2013.05.020

[23] Hong, Y., Zhang, H., Sun, J., Ayman, K.M., Hensley, A.J.R., Gu, M., Engelhard, M.H., McEwen, J.-S. and Wang, Y. (2014) Synergistic Catalysis between Pd and Fe in Gas Phase Hydrodeoxygenation of $m$-Cresol. ACS Catalysis, 4, 3335-3345. http://dx.doi.org/10.1021/cs500578g 
[24] Do, P.T.M., Foster, A.J., Chen, J. and Lobo, R.F. (2012) Bimetallic Effects in the Hydrodeoxygenation of Meta-Cresol on $\gamma-\mathrm{Al}_{2} \mathrm{O}_{3}$ Supported Pt-Ni and Pt-Co Catalysts. Green Chemistry, 14, 1388-1397. http://dx.doi.org/10.1039/c2gc16544a

[25] Huynh, T.M., Armbruster, U., Pohl, M.-M., Schneider, M., Radnik, J., Hoang, D.-L., Phan, B.M.Q., Nguyen, D.A. and Martin, A. (2014) Hydrodeoxygenation of Phenol as a Model Compound for Bio-Oil on Non-Noble Bimetallic NickelBased Catalysts. ChemCatChem, 6, 1940-1951. http://dx.doi.org/10.1002/cctc.201402011

[26] Huynh, T.M., Armbruster, U., Phan, B.M.Q., Nguyen, D.A. and Martin, A. (2014) The Influence of Cobalt in Bimetallic Ni-Co Catalyst Supported on H-Beta for Phenol Hydrodeoxygenation. Chimica Oggi-Chemistry Today, 32, 40-44. http://www.teknoscienze.com/Articles/Chimica-Oggi-Chemistry-Today-The-influence-of-cobalt-in-bimetallic-Ni-Co-c atalyst-supported-on.aspx

[27] Ravenelle, R.M., Schüßler, F., D’Amico, A., Danilina, N., van Bokhoven, J.A., Lercher, J.A., Jones, C.W. and Sievers, C. (2010) Stability of Zeolites in Hot Liquid Water. The Journal of Physical Chemistry C, 114, 19582-19595. http://dx.doi.org/10.1021/jp104639e

[28] Zhao, C., Kou, Y., Lemonidou, A.A., Li, X. and Lercher, J.A. (2009) Highly Selective Catalytic Conversion of Phenolic Bio-Oil to Alkanes. Angewandte Chemie International Edition, 48, 3987-3990. http://dx.doi.org/10.1002/anie.200900404

[29] Yoon, Y., Rousseau, R., Weber, R.S., Mei, D. and Lercher, J.A. (2014) First-Principles Study of Phenol Hydrogenation on Pt and Ni Catalysts in Aqueous Phase. Journal of the American Chemical Society, 136, 10287-10298. http://dx.doi.org/10.1021/ja501592y

[30] Huber, G.W., Iborra, S. and Corma, A. (2006) Synthesis of Transportation Fuels from Biomass: Chemistry, Catalysts, and Engineering. Chemical Reviews, 106, 4044-4098. http://dx.doi.org/10.1021/cr068360d 